http://jmscr.igmpublication.org/home/ ISSN (e)-2347-176x ISSN (p) 2455-0450 crossref DOI: https://dx.doi.org/10.18535/jmscr/v7i11.96

Journal Of Medical Science And Clinical Research

\title{
A Study on the use of Early Nasal Continuous Positive Airway Pressure (CPAP) in Preterm Neonates with Hyaline Membrane Disease (Respiratory Distress Syndrome)
}

\author{
Authors \\ Dr B.Lakshmi Parvathi, Dr A. Vineela, Dr P. Venu Gopal MD.Dch \\ Department of Paediatrics, Andhra Medical College, Visakhapatnam
}

\begin{abstract}
Introduction: HMD is the most common cause of respiratory distress in preterm neonates. Deficiency of pulmonary surfactant is one of the commonest factors contributing to development of RDS. CPAP as noninvasive respiratory support is an excellent option useful to avoid the harmful effects associated with invasive ventilation.

\section{Objectives}

1. To find the incidence of premature neonates (<37 weeks) in our hospital.

2. To find the incidence of HMD premature neonates with gestational age between 28-36Weeks.

3. To evaluate the effectiveness of early CPAP in preterm neonates with HMD.

Materials \& Methods: It is Longitudinal Observational study conducted for 1 year duration from January 2018- December 2018.50 inborn preterm neonates with diagnosed HMD admitted in SNCU, KGH were taken as subjects for this study..

Results: CPAP was admitted to 50babies out of total 130 inborn neonates diagnosed with HMD, from the period of 0-6hrs. Outcome with $80 \%$ success rate and $20 \%$ failed requiring higher mode of ventilation. The mean duration requiring CPAP in success group was $38.5 \pm 15 \mathrm{hrs}$ with range of 10-72hrs, whereas in failure group it is $9.0 \pm 1.7 \mathrm{hrs}$ with range of $8-12 \mathrm{hrs}$. The effectiveness of CPAP was found to be $100 \%$ in mild HMD, 93\% in moderate HMD and was only 46.67\% in severe HMD. Out of 10 babies who were ventilated $90 \%$ were less than 32 wks gestational age.

Conclusion: In our study we report that prematurity is the commonest cause for HMD. Its incidence increases with decrease in birth weight \& gestational age. Early nasal CPAP is useful in mild \& moderate $H M D$ with no significant effective outcome in severe HMD. It is safe, inexpensive and effective means of respiratory support in $H M D$.
\end{abstract}

\section{Introduction}

Respiratory distress syndrome (RDS) is the commonest cause of respiratory distress in preterm infants. Deficiency of pulmonary surfactant is one of the most important factors contributing to the development of $\mathrm{RDS}^{1}$. In immature lungs, the elevated surface tension resulting from surfactant deficiency leads to alveolar collapse at the end of expiration, atelectasis, uneven inflation and regional alveolar over distension. Typical for HMD is that the clinical signs develop gradually in the first hours after birth. It is assumed that breathing movements of the surfactant deficient lung generate shear 
forces to the epithelium of the terminal bronchiole, resulting in epithelial lesions. Subsequently fibrinogen and other serum proteins leak through the epithelial lesions into the alveolar space. These proteins inhibit surfactant function and hence cause progressive alveolar collapse ${ }^{2}$ producing the clinical picture of $\operatorname{RDS}^{3}$. Lower the gestation, higher is the incidence of RDS, accounting for nearly $80 \%$ incidence in preterm infants with gestation less than 28 weeks.

Continuous distending pressure (CDP) has been used for the prevention and treatment of RDS as well as the prevention of apnoea, and in weaning from IPPV. CPAP results in progressive recruitment of alveoli, inflates collapsed alveoli and reduces intrapulmonary shunt ${ }^{4}$. It increases the functional residual capacity (FRC) and in turn gaseous exchange. It reduces inspiratory resistance by dilating the airways. This permits a larger tidal volume for a given pressure, so reducing the work of breathing ${ }^{5}$. It regularizes and slows the respiratory rate. It increases the mean airway pressure and improves ventilation perfusion mismatch. It conserves surfactant on the alveolar surface ${ }^{6,7}$.

CPAP is applied via a face mask, nasopharyngeal tube, or nasal prongs, using a conventional ventilator, bubble circuit or CPAP driver. Bubble CPAP is a newer CPAP delivering system. It is CPAP delivered by CPAP system with underwater seal. It has been shown that CPAP delivered by underwater seal causes vibration of the chest due to gas flow under water, which is transmitted to infant's airway. These vibrations simulate waveforms produced by high frequency ventilation $^{8}$.

\section{Methodology}

The study was conducted at SNCU, King George Hospital, Visakhapatnam

50 Inborn neonates with clinically \& radiological diagnosed Hyaline membrane disease (HMD) with gestational age 28-36 weeks admitted to SNCU were subjects for this study.

\section{Inclusion Criteria}

- Preterm neonate (28-36weeks)

- RDS having onset within 6 hours of birth

- Skiagram of chest showing either poor expansion with air bronchogram or reticulo-granular pattern or ground glass opacity.

\section{Exclusion Criteria}

- All term neonates (>37Weeks age)

- Neonates with congenital malformations.

- Babies born to mothers receiving general anaesthesia, phenobarbitone, Pethidine and other drugs likely to depress the baby.

- Preterm born outside our hospital

- Babies with meconium aspiration syndrome \& birth asphyxia.

\section{Statistical Analysis}

Babies treated with nasal CPAP treatment were classified into two groups namely success and failure group and comparison between the groups were carried out as follows:

- Proportions were compared using chisquare $\left(\chi^{2}\right)$ test of significance. Proportion of cases belonging to specific group of parameter or having a particular problem was expressed in absolute number and percentage.

- The results were averaged (mean \pm standard deviation) for each parameter (duration of treatment, age at admission, age at treatment and $\mathrm{ABG}$ parameter) between the groups. Student ' $t$ ' test was used to find a significant differences between two means.

- In all the above tests, $\mathrm{p}$ value $<0.05$ is considered to be statistically significant.

\section{Results}

Total number of deliveries and preterm births ( $<37$ weeks) and incidence of Hyaline Membrane Disease (HMD) in Andhra Medical College during the study period i.e., from January 2018 to December 2018 were determined.

$>$ Total number of deliveries : 4050 
Total number of preterm neonates $(<37$ weeks): 503

$>$ Incidence of preterm neonates : $12.42 \%$

$>$ Total number of diagnosed HMD cases: 130

$>$ Incidence of HMD in neonates with gestational age between 28-34 weeks: $3.2 \%$

CPAP was administered to 50 babies from period of 0-6hrs of birth.

Table 1: Nasal CPAP treatment outcome among babies

\begin{tabular}{|l|c|c|c|c|}
\hline Total no.of & \multicolumn{2}{|c|}{ SUCCES } & \multicolumn{2}{c|}{ FAILURE } \\
\cline { 2 - 5 } babies treated & Number & Percent & Number & Percent \\
\hline $\mathbf{5 0}$ & $\mathbf{4 0}$ & $\mathbf{8 0}$ & $\mathbf{1 0}$ & $\mathbf{2 0}$ \\
\hline
\end{tabular}

The table shows the outcome in study group after early nasal CPAP. Among 50 babies, 40 improved with success rate of $80 \%, 10(20 \%)$ babies failed requiring higher mode of ventilation.

Table 2: Gender distribution among study group

\begin{tabular}{|l|c|c|c|}
\hline Gender & Success & Failure & Total \\
\hline Male & $24(75 \%)$ & $8(25 \%)$ & 32 \\
\hline Female & $16(88.8 \%)$ & $2(11.11 \%)$ & 18 \\
\hline \multicolumn{4}{|c|}{$\mathrm{p}>0.05$ Not significant } \\
\hline$\square_{2}=1.38$ & $\mathrm{df}=1$ & 10 \\
\hline
\end{tabular}

The success rate of $75 \%$ (24) is seen in males \& $88.88 \%$ (16) in females

Table 3: Effect of CPAP on babies based on gestational age

\begin{tabular}{|l|c|c|c|}
\hline Gestational age (weeks) & Total & Success & Failure \\
\hline $28-30$ & 12 & $5(41.67 \%)$ & $7(58.33 \%)$ \\
\hline $31-32$ & 30 & $28(93.30 \%)$ & $2(6.67 \%)$ \\
\hline $33-34$ & 8 & $7(87.50 \%)$ & $1(12.50 \%)$ \\
\hline \multicolumn{4}{|c|}{$\mathbf{p}>\mathbf{0 . 0 0 1}$}
\end{tabular}

Higher the gestational age more is the success rate with statistically significant difference between success \& failure groups.

Table 4: Effectiveness of CPAP based on time (mean duration of treatment in hours)

\begin{tabular}{|l|c|c|c|}
\hline Group & Number & $\begin{array}{c}\text { Hours } \\
(\text { range })\end{array}$ & Mean $\pm S D$ \\
\hline Success & $\mathbf{4 0}$ & $\mathbf{1 0 - 7 2}$ & $\mathbf{3 8 . 5} \pm \mathbf{1 5 . 4 0}$ \\
\hline Failure & $\mathbf{1 0}$ & $\mathbf{8 - 1 2}$ & $\mathbf{9 . 0} \pm \mathbf{1 . 7 0}$ \\
\hline
\end{tabular}

The ideal duration to wean off from CPAP was determined from the above results documented. The mean duration in success group was $38.5 \pm 15.4$ hours with range being 10-72 hours. Similarly mean duration of treatment in failure group was $9.0 \pm 1.7$ hours range being 8 -12hours.

Table 5: Effect of CPAP on SA (Silverman Anderson) score

\begin{tabular}{|c|c|c|c|c|c|c|}
\hline \multirow{2}{*}{$\begin{array}{l}\text { Total no.of } \\
\text { babies }\end{array}$} & \multirow{2}{*}{$\begin{array}{c}\text { SA score } \\
\text { before CPAP }\end{array}$} & \multicolumn{5}{|c|}{ SA score after 6hours of CPAP } \\
\hline & & 2 & 3 & 4 & 6 & 7 \\
\hline 16 & 4 & $5(31.2 \%)$ & $7(43.8 \%)$ & 0 & $4(25 \%)$ & 0 \\
\hline 34 & $\geq \mathbf{5}$ & $2(5.90 \%)$ & $18(52.9 \%)$ & $8(23.5 \%)$ & $5(14.7 \%)$ & $1(2.90 \%)$ \\
\hline 50 & & $7(14 \%)$ & $25(50 \%)$ & $8(16 \%)$ & $9(18 \%)$ & $1(2 \%)$ \\
\hline
\end{tabular}

Out of 16 babies who were in SA score 4, 5 babies improved to score 2, 7 babies to score 3 and remaining 4 babies worsened to SA score of 6 and required ventilation. Out of 34 babies who had a score of $\geq 5$ before nasal CPAP, 2 babies improved to score 2, 18 babies improved to score 3, 8 babies improved to score 4 after 6 hours of nasal CPAP. So there is statistically significant improvement with early nasal CPAP in SA Score.

Table 6: Effect of CPAP on ABG analysis

\begin{tabular}{|l|c|c|c|c|}
\hline \multirow{2}{*}{$\begin{array}{l}\text { ABG } \\
\text { parameters }\end{array}$} & \multicolumn{2}{|c|}{$\begin{array}{c}\text { Before early nasal CPAP } \\
\text { mean } \pm \text { SD }\end{array}$} & \multicolumn{2}{c|}{$\begin{array}{c}\text { After early nasal CPAP } \\
\text { Mean } \pm \text { SD }\end{array}$} \\
\cline { 2 - 5 } & Success & Failure & Success & Failure \\
\hline pH & $7.26 \pm 0.079$ & $7.31 \pm 0.109$ & $7.37 \pm 0.0$ & $7.31 \pm 0.118$ \\
\hline ' $t$ ' value & \multicolumn{2}{|c|}{1.433} & \multicolumn{2}{c|}{2.00} \\
\hline 'p' value & \multicolumn{2}{|c|}{0.178} & \multicolumn{2}{c|}{0.073} \\
\hline PO2 & $57.66 \pm 10.58$ & $55.93 \pm 10.96$ & $80.48 \pm 7.5$ & $42.16 \pm 18.83$ \\
\hline 't' value & \multicolumn{2}{|c|}{0.451} & \multicolumn{2}{c|}{6.309} \\
\hline 'p' value & \multicolumn{2}{|c|}{0.659} & \multicolumn{2}{c|}{0.001} \\
\hline PCO2 & $41.31 \pm 11.14$ & $36.99 \pm 10.42$ & $30.62 \pm 6.6$ & $38.40 \pm 9.73$ \\
\hline 't' value & \multicolumn{2}{|c|}{1.147} & \multicolumn{2}{c|}{2.389} \\
\hline 'p' value & \multicolumn{2}{|c|}{0.270} & \multicolumn{2}{c|}{036} \\
\hline HCO ${ }_{3}^{-}$ & $18.37 \pm 0.97$ & $18.56 \pm 0.81$ & $20.50 \pm 1$ & $17.15 \pm 0.83$ \\
\hline 't'value & \multicolumn{2}{|c|}{0.64} & \multicolumn{2}{c|}{10.82} \\
\hline 'p'value & \multicolumn{2}{|c|}{$>0.05$} & \multicolumn{2}{c|}{} \\
\hline
\end{tabular}


The results showed significant increase in oxygenation \& bicarbonate levels indicating the positive effect of CPAP on neonates.

Table 7: Effect of CPAP on babies categorised based on HMD

\begin{tabular}{|c|c|c|c|}
\hline HMD grading & Success & Failure & Total \\
\hline Mild & $6(100 \%)$ & 0 & 6 \\
\hline Moderate & $27(93.10 \%)$ & $2(6.9 \%)$ & 29 \\
\hline Severe & $7(46.67 \%)$ & $8(53.33 \%)$ & 15 \\
\hline & 40 & 10 & 50 \\
\hline
\end{tabular}

The result therefore suggests the usefulness of CPAP in mild and moderate HMD babies. In severe grade HMD the success rate was only $46.67 \%$.

Table 8: Effect of antenatal steroids in outcome

\begin{tabular}{|l|c|c|c|}
\hline $\begin{array}{l}\text { Steroids } \\
\text { received }\end{array}$ & Success & Failure & Total \\
\hline YES & $26(92.86 \%)$ & $2(7.14 \%)$ & 28 \\
\hline NO & $14(63.63 \%)$ & $8(36.37 \%)$ & 22 \\
\hline \multicolumn{4}{|c|}{$\mathbf{p}<\mathbf{0 . 0 5}$, Significant }
\end{tabular}

It is found that success rate was $92.86 \%$ in babies of mothers who had received antenatal steroids, whereas only $63.63 \%$ of the babies in whose mothers did not receive antenatal steroids (statistically significant $\mathrm{p}<0.05$ ). Hence, antenatal steroids in mother had definite role in better outcome of HMD when treated with CPAP.

\section{Discussion}

The incidence of prematurity in our study is $12.42 \%$ as compared to National Statistics of 10$12 \%$ in India $^{10}$. The incidence of HMD in this study is $3.2 \%$. According to NNPD 2002-03 report ${ }^{9}$ the incidence of HMD in our country was $1.3 \%$ of all live births. In our study50 preterm babies with gestational age 28 - 34 weeks with HMD were treated with early nasal CPAP. Out of 50,40 babies $(80 \%)$ were effectively managed with early nasal CPAP alone. Remaining 10 (20\%) had to be intubated and required more invasive mechanical ventilation

Out of 10 babies who required ventilation $90 \%$ of the babies were less than 32 weeks gestation age; remaining $10 \%$ were between 33-34 weeks.
Analysis of these results showed that outcome is better with increased gestational age $(\mathrm{p}<0.005)$. Jacobsen et $\mathrm{al}^{11}$ have shown better outcome in babies with gestational age of $<33$ weeks. They found significant reduction in mechanical ventilation from $76 \%$ to $35 \%(\mathrm{p}=0.00001)$.

Blood gas analysis was the other parameter, which helped us to decide success and failure on early nasal CPAP. A study by Harris $\mathrm{H}$ et $\mathrm{al}^{12}$ found a significant improvement in mean $\mathrm{PaO} 2$ (from 47 to $80 \mathrm{~mm} \mathrm{Hg}$; $\mathrm{p}<0.001$ ) with no significant change in $\mathrm{PaCO} 2$ or $\mathrm{pH}$.

Boo NY et $\mathrm{al}^{13}$ in a recent study determined the predictors associated with failure of nasal continuous positive airway pressure (CPAP) in the treatment of respiratory distress syndrome (RDS). They showed that only three risk factors were significantly associated with failed CPAP. These were: moderate or severe RDS (odds ratio 5.9; 95\%; CI 1.5-50.7); and pneumothorax during CPAP therapy (odds ratio 6.9; 95\%; CI 1.1-41.7). In our study $80 \%$ of the babies who failed had severe RDS.

A success rate of $92.86 \%$ was found in babies of mothers who had received antenatal steroids with ' $p$ ' value $<0.05$ (significant) in our study. Sandri F et $\mathrm{al}^{14}$ has shown trend towards greater failure in babies who had not received antenatal steroids $(\mathrm{p}=0.02)$.

\section{Conclusion}

In developing countries like ours, there is high burden of prematurity and sub-optimal use of antenatal steroid administration resulting infrequent HMD. In our study, we report that prematurity is the commonest predisposing factor for HMD. Its incidence increases as gestational age decreases. Early nasal CPAP is useful in mild and moderate grade HMD. It may not be a replacement for assisted respiratory support (ventilation) in severe HMD. Nasal CPAP is found to be effective in babies of mothers who had received antenatal steroids. Nasal CPAP is safe, inexpensive and effective means of respiratory support in HMD. Use of early nasal 
CPAP which is simple, non-invasive, has low capital outlay and does not require expertise, is the option for us where most places cannot provide invasive ventilation

\section{References}

1. Avery ME, Mead J. Surface properties in relation to atelectasis and hyaline membrane disease. AMA journal of diseases of children. 1959;97(5, Part 1):517-23.

2. Jobe A, Ikegami M, Jacobs H, Jones S, Conaway D. Permeability of premature lamb lungs to protein and the effect of surfactant on that permeability. J ApplPhysiol 1983; 55: 169-176.

3. Whitsett JA, Pryhuber GS, Rice WR, Warner BB, Wert SE. Acute respiratory disorders. In: Avery GB, Fletcher MA, MacDonald MG (eds), Neonatology: Pathophysiology and Management of the Newborn, 4 ed. Philadelphia: J.B. Lippincott Company; 1994: 429-452.

4. Chernick V. Continuous distending pressure in hyaline membrane disease: Devices, disadvantages and a daring study. Pediatrics 1973; 52: 114-15.

5. Harris TR, Wood BR. Physiologic Principles. In: Goldsmith JP,Karotkin EH eds. Assisted Ventilation, 3rd edn., Philadelphia; WB Saunders, 1996; 21-68.

6. Michna J, Jobe AH, Ikegami M. Positive end expiratory pressure preserves surfactant function in preterm lambs. Am J RespCrit Care Med 1999; 60: 634-639.

7. Lawson EE, Birdwell RL, Huang PS. Augmentation of pulmonary surfactant secretion by lung expansion at birth. Pediatr Res 1979; 13: 611-614.

8. Lee US, Dunn MS, Fenwick M et al. A comparison of underwater bubble continuous positive airway pressure (CPAP) with ventilator derived CPAP in preterm neonates ready for extubation. Biol Neonate 1998; 73: 69-75.

9. Report of the National Neonatal Perinatal Database. National Neonatology Forum, India; 2002-03.

10. Meharban Singh. Care of the Newborn. 6th edn., page. 219.

11. Prashanth S Urs, Firdose Khan, Maiya PP. Bubble CPAP - A primary respiratory support for respiratory distress syndrome in newborns. Indian Pediatrics 2009; 46: 409-411.

12. Finer NN, Carlo WA, Walsh MC, Rich W, Gantz MG, Laptook AR, et al. Early CPAP versus surfactant in extremely preterm infants. The New England journal of medicine. 2010;362(21):1970-79

13. Boo NY, Zuraidah AL, Lim NL et al. Predictors of failure of nasal continuous positive airway pressure in treatment of preterm infants with respiratory distress syndrome. J Tropical Pediatr. 2000 Jun; 46(3): 1725.

14. Sandri F, Ancora G, Lanzoni A et al. Prophylactic nasal continuous positive airways pressure in newborns of 28-31 weeks gestations : multicenter randomized controlled clinical trial. Arch Dis Child Fetal Neonatal Ed. 2004 Sep; 89(5): F3948. 